\title{
A Case for Contrast as a Catalyst for Change
}

\author{
Louise Young, University of Western Sydney, NSW, AUSTRALIA \\ Lynne Freeman, University of Technology, NSW, AUSTRALIA
}

\begin{abstract}
This is a qualitative, largely reflective, interpretive case study of our evolution from teachers of market research to educational collaborators who work with students to co-develop qualitative researchers. This case both explores the ways to extend and improve qualitative research and researchers and presents a more general, interpretivist approach to problem-solving. The case is mixed method. It reports the combination and interpretation of reflective elements including articulating our individual memories and inter-relating these in a series of discussions where we also considered the nature and meaning of our educational approaches and the effectiveness of what we are doing. It also reports elements of the document analysis of our separate and collective teaching materials and the texts and the literature associated with qualitative research and teaching. The case illustrates the effectiveness of using "contrast" as a mechanism for the development of teaching, learning and research skills. The particular relevance of contrast in teaching qualitative research methods generally and interpretivist qualitative approaches in particular is also addressed. The reporting of this case relies on the interpretation of events that occur through time. In addition to simply reporting and interpreting our reflections, narrative event sequence analysis methods (Abbott 2001, Abell 1998, 1993) are used to evaluate the evolution of expertise and approach that are at the heart of this case. These analytical approaches allow us to move beyond the reporting of history to consideration of key factors that drive it. This in turn allows insights of this to be utlized in other contexts. This case also highlights the substantial contribution of the contributions the commercial sector into our teaching (and research). The case concludes with reflection on the nature of qualitative discovery within our teaching that has emerged. It is spontaneous, messy, conflicting and surprising. We attempt to communicate this to students and to engineer situations where we are messy, conflicted and conflicting and surprised! It suits us.
\end{abstract}

Keywords: Case Study, Qualitative Research, Ontology

\section{Background and Method}

$\mathrm{T}$ THS PAPER IS about the evolution of the teaching philosophy and teaching methods for a qualitative research methods subject and reports a reflective history of the collaboration between the two authors that led to this. However in contrast to many papers which focus on pedagogy, the tone of this paper is descriptive rather than prescriptive. Our insights are presented within a case study reporting the evolution of a qualitative methods subject and of our associated skills. The case considers the meaning and impact of events which drove this process. Emerging insights have important implications for the stature of qualitative research in marketing academia - in particular the inclusion of interpretive ontologies.

There have been a number of conceptualisations in the education literature which consider what the drivers of evolution in teaching practice are. Some consider the environmental drivers of change. Changes in technology (Collins, 1991; Means, Olson, \& Singh, 1995; Mehlinger, 1996; Newman, 1992; Sheingold, 1991 in Dexter, Anderson and Becker 1999) or directed by institutions such school boards or accrediting bodies (Fullan 1992 in Dexter, Anderson and Becker 1999) or research-led changes in pedagogy are considered in this way. These approaches see change as externally or systemically motivated and driven. While valuable these are not the focus of this work.

Instead within our case we explore the drivers of educational change in terms of the growth process of interacting peers. There is also considerable work in this area. The constructivist model of learning highlights the understanding emerging when an educator acquires and organizes new information. This new learning shapes and is shaped by prior schema (Fosnot, 1996).

We argue that this process is "complex." Complexity theory is concerned with open, non-linear systems (Rosenhead, 1998). Non-linear systems will act in either predictable or non-predictable ways with unpredictable outcomes. When we look at a system as open we are recognising that small, non-purposive components can interact and become purposeful wholes (Lissack, 1999). Complexity theory recognises little things can have big consequences and big events small ones (Phelps and Hase, 2002) and that behavioural effects are not consistent (Hase 2005). Thus, change is emergent, self-organised, adaptive and dynamic. Complexity is a useful and usable perspective for our experiences in that it represents 
the non-linearity of thought that emerges in progressive innovation. Complexity allows us to consider the nature of processes and occasions that present opportunities for innovation of our teaching, however, we can not predict what will be learnt. Notions of feedback and "feed-forward" which are discussed in complexity writing in the education literature (e.g. by Phelps and Hase, 2002) also provide justification for considering and creating reflective learning experiences.

While a few complexity-oriented educationalists refer to reflection in their work (Bloom, 2001; Gough, 1999; Stacey, Griffin \& Shaw, 2000), it is seldom used as a framework for reflective research and practice. However reflection provides considerable scope for fostering and analyzing evolution of practice in ways that are congruent with complexity theories (Phelps 2005). This research uses a reflective action research approach which is in line with complexity theory. Action research is an emergent process in that theory is developed along the way and it is essentially data driven. Each action cycle is dependent on the outcomes of the previous cycle (Hase 2005). This approach is consistent with the research approach utilized here - that of joint, iterative reflection.

The context of the case is the university-level teaching of qualitative research methods by two educators working together. Over the years there has been limited work done that looks at the development of qualitative teaching and this is combined with a very diverse set of opinions as to what the basis of qualitative enquiry is and how the teaching of it should be approached (Colon et al 2000, Rist 1983). As there is little literature and the instructor starts with students who have had no practical or philosophical experience upon which they can build (Webb and Glesne 1992), there much rhetoric but little practical advice to those that would teach more than the rudiments of qualitative researching and interpretation (Rist, 1983). We therefore argue this paper and the case study contained within it addresses an important gap.

\section{Methodology}

Over the seven years that this subject has been developed we have built a portfolio of skills and resources. The skills built have been observed (as we most often work together in the class room) and feedback/discussion as to effectiveness has occurred throughout. The resources have been archived and continuously returned to. This case study has been developed by first systematically gathering and articulating our memories (and includes notes made at meetings and emails) and inter-relating our individual perspectives in a series of discussions. During these we also considered the nature and meaning of our educational approaches. Subsequent analysis included relating these articulated and cross-checked memories to an analysis of our separate and collective teaching materials and to the texts and literature associated with qualitative research and teaching.

The articulation process included little dissention. As there has been a continuous process of reflection and feedback over a number of years, the combining of these into a cogent history is a logical next step. Analysis as to the determination of which incidents were critical and their impact was slightly more complex. A decision rule was developed which made the inclusion criteria one of bringing in material that enabled a broad sketch of the case context (such that the process was coherently linked) and/or where a number of critical incidents co-occurred and/or where effects could be traced back to particular activities that caused them.

This approach was combined with historical sequencing to identify the mechanisms that drove the process of subject development and to thus enable some generalizability. The key mechanism identified using this process was that it was the differences between the subject co-developers and the way that these were handled that were the central driver of evolution. The articulated discussion and teaching materials were then re-analyzed for a final interpretation of the case material.

\section{The Genesis of Our Qualitative Teaching}

Most university marketing degrees incorporate the teaching of market research methods. However the focus of these subjects is most often on survey methodology. Only a brief time is given to all other methods and they are usually presented as means to assist in generating quality survey outcomes. Teaching of research methods is often simple training, i.e. the basic tools to collect and analyze data are presented but there is little or no sense of the implications for theory and measurement of using one method over another. The ontology that accompanies this training is likely to be firmly (though implicitly) positivistic and the idea of alternative stances with associated methods of doing research is not considered. We too taught in this way.

However we each came to see the importance of teaching qualitative research methods to better meet students' and industry's' needs. We were teaching parallel tracks of a project-based market research subject where a group project was undertaken for an organization seeking market research. ${ }^{1}$ During this

\footnotetext{
${ }^{1}$ Applications of Market Research (AMR) is entirely a group-based project completed by a class of 25-36 students who are placed in one of three to six groups of four to seven members each.
} 
period, we were ever-more-frequently approached by organizations that had research problems that required qualitative research. Initially we refused these, as surveys enabled student application of the skills they had learned in an introductory market research subject which did not include any training in qualitative methods. Conventional wisdom also dictated that quantitative projects were more straightforward to manage and assess.

But we were in danger of being "left behind." Qualitative research was being more widely used and commercial research providers were utilizing increasingly sophisticated qualitative techniques with good effect. Cost, ethics, more rigorous privacy legislation and decreasing cooperation by the over-researched community was rapidly changing the market research environment. The industry and academic research environment was one where structured instruments, particularly mail surveys received less response. We each increasingly used qualitative research methods in our own research to overcome these problems and became increasingly impressed with its power and capability. These factors led us to develop effective methods in line industry's preferences and practices, i.e. training in qualitative techniques.

Our reflections identify that here is where the value of "contrast" in teaching first became apparent. Each of us began trying different approaches to student training that reflected our research interests. Lynne Freeman (LF), coming from the commercial research sector and with research interests in consumer behaviour and advertising, developed training methods for group interviewing. In contrast, Louise Young (LY) had some consulting experience but was primarily an academic researcher and working in business-to-business marketing areas. She focused on developing diverse depth interview skills for this context and on development of systematic and simple analysis approaches that could be communicated to inexperienced in a short time frame, including the use and combination of multiple sources of data into a case study. An example is a interviewer's briefing document was developed by LY that combined practical (e.g. don't forget backup power sources for your tape recorder) with needing to apply a deeper understanding of the nature of qualitative research to the immediate problem (e.g. questioning is guided by whether you are trying to understand how much difference there is between informants or are trying to build an overall picture of a particular phenomena such as a distribution channel where each informant will contribute a piece to the puzzle). This is reported in further detail in Wilkinson and Young (2004).

Our parallel paths provided a fertile context for developing capabilities for qualitative training of students. As already indicated this occurred via the informal swapping of stories of our successes and adapting and adopting each others' techniques and insights. The substantial benefits we each accrued led to more systematic swapping of ideas and experiences and ultimately to sessions where we jointly reflected on reasons for the effectiveness of our innovations in a given context (in line with de-briefing sessions that might occur after fieldwork). This is in line with information theorists who argue that both the ad hoc and systematic verbal exchange of ideas is a key mechanism for innovation (e.g. Brown and Duguid 2000).

From this process came the development of a joint portfolio of research training techniques whereby we could train student researchers in qualitative techniques who could then complete a commercial project - all in the available sixteen weeks. (We were constrained by the semester framework of the institution.) Training consisted of workshop sessions dealing with the management of a qualitative project, development of question guides and recording frames for observation, practicing interviewing and analysis of the effectiveness of various questioning techniques, analysis of notes, summaries and transcripts and communication of results in presentations and reports. Now within this project-based subject, twothirds of student projects include a substantial qualitative component. Student evaluation indicates that satisfaction with the subject has risen as has their perception of the relevance of generating and applying research findings to marketing problems. These experiences thus highlighted possibilities for developing qualitative research skills in other cohorts.

\section{The Genesis of Higher Degree Qualitative Research Education}

The success of providing undergraduate qualitative training encouraged us to develop related initiatives for Higher Degree Research (HDR) students.

There was no systematic qualitative training required for HDR business students, this is similar to the practices of most Australian institutions. Historically this had made sense, as HDR students were strongly encouraged to undertake surveys that were more publishable (in mainstream US journals). Also there were no experienced supervisors with qualitative skills. This is not unique to marketing, Eakin and Mykhalovskiy (2004) found a similar situation in the health sciences. And, there was no demand. Traditionally most students had had little exposure to anything but the most superficial qualitative methods and therefore were not disposed towards undertaking in depth qualitative research.

Complexity theory tells us that innovation often occurs when critical incidents occur in close proximity. Here two things happened simultaneously. While 
we were building expertise in qualitative teaching with undergraduates the nature of HDR student applicants changed. Increasingly HDR students presented themselves from commercial and nonmarketing backgrounds and were interested in doing non traditional research which incorporated substantial qualitative research. This gave us the opportunity to design an academically orientated qualitative research methods subject.

Again innovation was driven by the juxtaposition of seemingly unrelated factors. Our orientation to that date had been entirely concerned with how to teach students to quickly and appropriately collect fairly simple, commercially valuable information using qualitative methods. For HDR students we needed to move beyond simple training and teach about qualitative research (along the lines of teaching theories of measurement rather than simple rules to guide research behaviour). Also, we had never collaborated in research and were not aware of how different our ontologies were. We discovered that a strong relativist and a critical realist with some positivistic leaning have rather different ideas about the teaching and the doing of qualitative research!

Once again our contrasts proved valuable. Rather than compromising, we developed a subject that celebrated diversity of ontology and method. We found that a foundation of common ground - belief in the importance of self-insight, serendipity and rigor (discussed below) - enabled us to educate students in the core values of doing qualitative research. At first unintentionally, in the classroom we found ourselves engaging in dialogue that not only exposed students to multiple possibilities in approaching research but gave both of us insights into our own approaches. As Burbules (1993) says, "Dialogue is not fundamentally a form of question-answer communication, but an engaging social relation" and this is what we developed. Our demonstration of diversity challenged students to consider their own philosophies of research and make informed choices about research method based on these and contributed to the development of a respect for those with different ontologies - something that is unfortunately sometimes lacking in the academic marketing community. For many of the students this was their first exposure to a classroom situation where dialogue between the presenters of the material was the foundation for its delivery. The students became eager participants, generating many of the discussions, frequently through interrogating one or other of the presenters as to their response to the material being presented by the other. These HDR students have enjoyed and benefited from having had the opportunity to develop their own rather than a prescribed approach.

\section{Innovation in Qualitative Research Education Emerging from Contrast}

An informal review of the topics covered in the burgeoning short courses and subjects about qualitative research for academic research showed us that existing subjects focus, as we had, on training - how to design research, collect information, analyze this and apply it to a research problem. This was reflected in our earliest versions of qualitative methods for HDR students. However our approach has evolved and reflects the processes of innovation that we have articulated throughout this paper. The learning of qualitative research methods requires articulation and reflection for innovation to occur. In other words at the center of a qualitative subject is the development of skills that enables understanding of oneself as a researcher and the ability to communicate this understanding to others.

Development of an environment of self-development requires an understanding of the nature of qualitative enquiry with all of its richness, serendipity, "mess" and contradiction and the facilitation of safe context where students can experiment with the related approaches. To facilitate the development of such an environment we first debate and discuss these issues with our students. This is followed by training them in the meticulous reflection of one's own evolution as a researcher and the documentation of this.

We have come to see this as the main tenant of our approach - that continuing documentation of process is at the center of rigor in good qualitative research. To build the credibility of qualitative research requires that the results that emerge and the process that led to these results are trusted. Some texts have proposed that this means that qualitative research should reflect, as much as possible, the processes we find in quantitative research methods (e.g. Miles and Huberman, 1993). Such authors advocate practices such as large sample sizes, reductionist analytical frameworks, working within strict, pre-determined theoretical guidelines, etc. This, it is argued, reduces bias and increases replicability.

While we expose students to this stance we also present our own - that such approaches decrease validity and turn potentially good qualitative research into second rate quantitative research (as do texts such as Flick 2006). In addition we argue that the serendipity that is at the heart of great qualitative research is lost in such approaches and the potential for discovery and knowledge substantially diminished (see Wilkinson and Young 2004). Central to rigor in our approach is a meticulous "chain of evidence." We advocate detailed documentation from the beginning of a project including articulating preliminary thoughts and ideas, their development into decisions about how to design research and the 
experiences that guide and influence the research and analysis process. This enables the reasoning that led to particular decisions about focus and approach to be traced and communicated. The reflective and record-keeping journal we advocate also charts the development of qualitative thinking and enables students to reflect on their own progress as researchers. As such it facilitates a core goal of the subject the understanding self as a researcher and the ability to communicate this.

In the main reflective journals have been used for fieldwork, i.e. to highlight observations and issues occurring before, further and after data collection. We argue that extending this approach improves all stages of the research process and encourages a more non-linear approach - as articulation of issues emerges encourages researchers to continue to consider and re-explore previous assumptions and decisions. In particular reflection and articulation of the process of analysis including the choices made and underlying reasoning leading to these, improves and validates the use of interpretive techniques. Without the continuing review of reflections on analysis, students avoid interpretive methods and use more mechanical content analysis/modeling techniques that they (and often their supervisors!) perceive can be verified and justified. With the "chain of evidence" that the journal helps to provide, the students both undertake a range of interpretive analyses and better articulate this process in their final work. To reinforce this in the minds of the student we attempt to acquaint them with the practices of academic and industry researchers. For example, a presentation of cutting edge data capture and interpretation methods by one of Australian's leading commercial qualitative research confirmed in students' mind that of what is "practical" in solving industry research problems is also spontaneous, messy, conflicting and surprising and in many ways ahead of what is happening in academia.

The concept of the individual journey as a researcher is one that qualitative researchers have long held to be of interest both from the perspective of increasing the transparency of the process and for self development. Our experience suggests that it is an approach that is of value to all HDR students regardless of approach. Even the most positivistic of students, once exposed to the discipline of a field journal is likely to adopt it for all aspects of their research, both qualitative and quantitative. For example, one of the most positivistic of our past students is now never found without her journal. She is not and doesn't want to be a qualitative researcher but she is an avid journal keeper and brandishes it, with all of the zeal of the convert, noting down insights, references and directions for future research.
The process of reflection, review and rigor that is at the heart of the journal is reflected in the subject's non-linear organization. Themes associated with the underlying philosophy of thinking and researching qualitatively are returned to throughout the subject, to highlight our core message of the self-aware, serendipitous, yet rigorous researcher as being at the heart of the qualitative process. This stable core contrasts with the contrasting views that increasingly emerge when we discuss theoretical frameworks, research design, various data collection methods and analysis. Here discussion can get quite heated when, for example, LY trains students in computer-aided analysis and discusses the value of collaborative research teams for research validation and LF indicates that it is the personal and solo interpretation that is of value for the audience of qualitative research.

\section{Interpretation and Validation of the Reported History}

With the story of the development of the qualitative methods subject told, we turn to a description of our own chain of evidence in reporting and interpreting the events we have described. The role of participantobserver is always a problematic one, particularly with respect to balancing insight and objectivity in reporting. While the methods used for constructing this case study have attempted to verify the reported events and their sources, we are limited in the amount of detail and number of incidents that we can use to verify the bottom-up, self organizing process that we believe characterizes the development of our subject. An additional form of interpretive analysis provides an additional check and provides a little more of the specifics of the processes we have described.

As this is the report of a sequence of historical events, we use the interpretation of sequence analysis for verification. For this we first articulate the sequence of events. We then articulate the links between events in line with the approach developed by Abell (1987), where the assumption is that macrolevel events result from micro-level interaction between actors. The nature of the activities and their outcomes are interpreted in terms of their intentionality, force (active-passive), and conditionality and consequence. (Abbott 2001; Abell 1993; 1987).

Figure 1 summaries the key events that have been described. An evolving macro environment creates the need and demand for a qualitative methods subject and the willingness of the institution to supply it. The macro activities of the authors - their pre existing teaching and research capabilities and previous shared experiences precipitate the recognition of the opportunity and development of the subject in line with the evolving macro environments. The micro 
level interactions of LY and LF are critical - coteaching, sharing information and later their dialogues as a key teaching strategy - in determining the events unfold as they do. These micro processes combine and recombine to lead to innovation in the subject. It is the relationships between these microprocesses that are critical - as highlighted by the centrality of the contrast between the principle architects at each juncture as a facilitating mechanism. Many of the micro processes are continuing (as indicated by feedback loops to themselves). This means that the activities continue and continue to provide input in subsequent events.

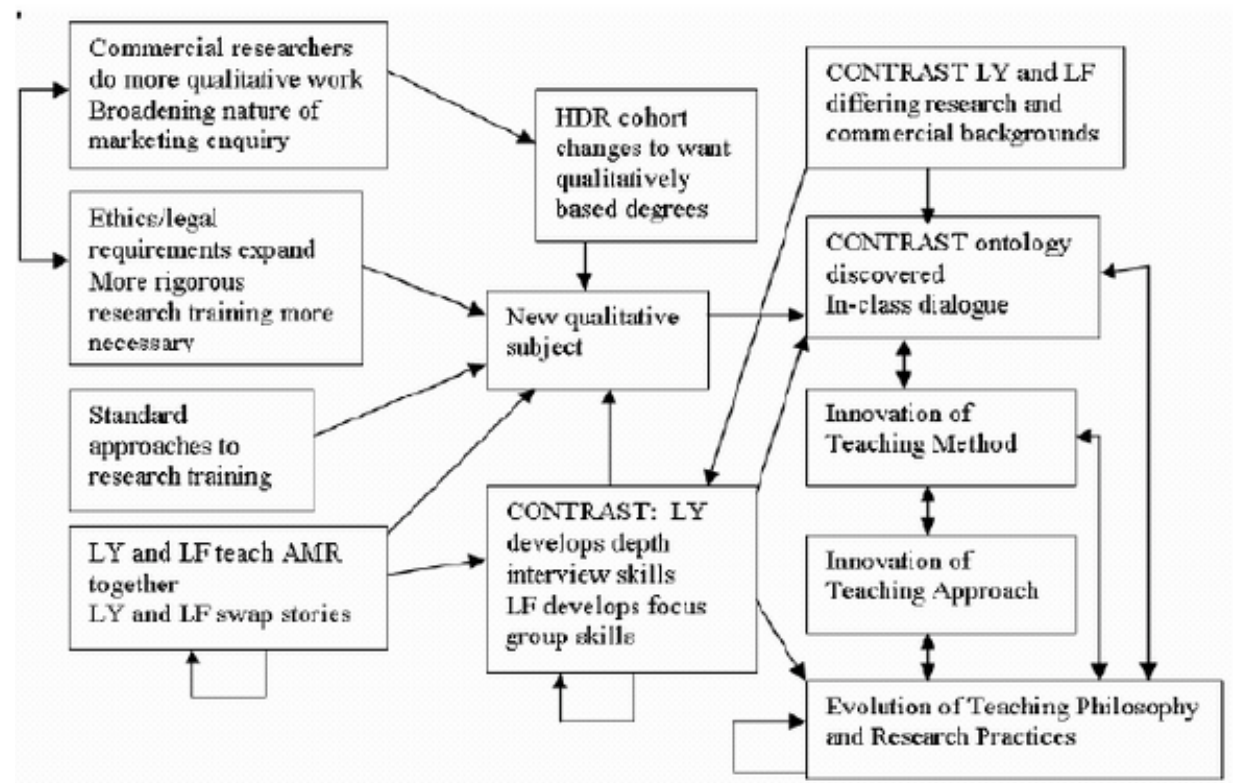

Figure 1: Reported Sequence and Causality of Events

Also it should be noted that the innovation itself creates innovative possibilities. It is through innovation of teaching method (i.e. working with students to enable them to think as qualitative researchers versus teaching them methods of doing qualitative research) that the possibilities of teaching using reflective journals emerged. In turn this facilitates the emergence of new philosophies of teaching and research, e.g. the importance of creating chains of evidence. Note also that there is continuing evolution (indicated via the two way arrows). The system is self-replicating. That is, the process currently in place enables continuing evolution/innovation of the subject.

The events were further analyzed using Ethno2 (www.indiana.edu/ socpsy/ESA/home), an event structure analysis program, to check the logical consistency of the recalled events and the projected relationships between them. The program searches for ambiguities between the reported sequence of events and the analyst's reports of causality between them. Potential problems that may be identified include an event's causality not being "used" by subsequent events, event's causality being "depleted" (hence another similar event or the same event needing to happen again to for there to be continuing impact) and the impossibility of all preconditions being satisfied and thus the impossibility of an event occurring as reported (requiring the causal structure and/or critical events to be rethought) (Heise and Lewis 1988). The process depicted in Figure 1 was found to be logically consistent by the criteria of the program, thus providing some validation of the interpretation of our self-reports.

\section{Discussion and Conclusion}

This paper presents a case study which illustrates reflection in action (where reflection and resultant change occur almost simultaneously) and reflection on action (where reflection is of our own and each others' actions in a longer time frame) (Schön 1983, 1985 as discussed by Hatton and Smith 1995). Reflection has been identified as central to action research and action learning (Carr and Kemmis 1990; Kemmis 1985; Kemmis and McTaggart 1988) and it plays a central role in experiential learning (Kolb 1984; Boud 1989), whereby knowledge is created by the transformation of experience through observation or reflection.

The process that we have described is richly reflective and reflexive. It is via reflexivity that reflection allows changes. Reflexivity includes the process of reacting in a way that allows values, beliefs and assumptions to be challenged and changed (Phelps 2004). Within a collaborative relationship we have challenged each others' contrasting beliefs and practices and gained insights that enabled our teach- 
ing practice development. This is at variance with standard team-teaching - "a situation in which two teachers share a class and divide instruction between them" (Richards, et al 1992: 375). Instead of dividing up the work we actively provide learning synergy by covering the same material from contrasting research stances.

The dialogue that we orchestrate to discuss the implications of our different "world views" and practices is an important learning and development tool (in line with the Anderson-Hunt debates of the 1980s of the relativists versus the positivists and the subsequent emergence of realism in the core of marketing philosophy; see Anderson 1986, 1988a, 1988b, Hunt 1984, 1990, 1992 Peter, 1992, Siegel 1988, Zinkman and Hirshman 1992).

As much as possible we attempt to reflect the nature of qualitative discovery within our teaching. It is spontaneous, messy, conflicting and surprising. We attempt to communicate this to students and to engineer situations where we are messy, conflicted and conflicting and surprised! We also attempt to incorporate the qualitative thinking and good practice of the commercial sector into our teaching and research. In contrast with much of marketing where business draws knowledge of cutting edge processes from academia, we believe that in qualitative method the reverse is true. It is the practitioners who are in the main leading the charge and we are often their students (see for example Ereaut and Imms 2004, Whiting 2005).
The synergies that can emerge in the interactions of our teaching and our academic and commercial researcher selves are captured in the metaphor of "honey bees" (Tinson 2005) where the symbiotic relationship of bees and flowers is considered. We see ourselves as bees, pollinating various research and teaching sectors with ideas drawn from others'. Also as this case repeatedly demonstrates our contrasts bring the benefits of diversity (as discussed by Wilkinson and Young 2002) but we are able "pollinate" each other. The analysis of our process of evolution highlights factors that can be used by others in the development of their teaching and research, both generally and more particularly in the context of qualitative research methods. While the history and context issues we report are unique, many of the specific teaching innovations reported here can be applied by others.

And, we argue that the "honey bees" metaphor can be taken further. The social properties of bees further reflect elements of qualitative enquiry. Bees have evolved cooperative strategies to improve their foraging behaviour that depend on imprecise direction, the clustered texture of their environment and the variety of bees in a hive (Beekman and Wilkinson 2004). This captures nicely our conceptualizations of and approaches to qualitative research - both as educators and researchers - and will continue to be captured in future research and teaching development.

\section{References}

Abbott, A (2001), Time Matters: on Theory and Method . Chicago: University of Chicago Press.

Abell, P. (1987), The Syntax of Social Life: Theory and Method of Comparative Narratives. Oxford: Oxford University Press

Abell, P. (1993), "Some Aspects of Narrative Method," Journal of Mathematical Sociology, 18 (2-3) 93-134.

Abell, P (1998), "Causality, and Low Frequency Complex Events: The Role of Comparative Narratives," in ISA Conference - Montreal Vol. available - http://www.lse.ac.uk/collections/IIM/publicationsDownloadablePapersAndTalks.htm

Anderson, P. (1986) "On Method in Consumer Research: A Critical Relativist Perspective" Journal of Consumer Research Sept $155-173$

Anderson, P. (1988a) "Relative to what - That is the Question: A Reply to Siegel" Journal of Consumer Research June 1337

Anderson, P. (1988b) “Relativism Revidivus: In defense of Critical Relativism” Journal of Consumer Research December, 403-6

Beekman, M. and Wilkinson, I. (2004) "What Can Social Insects Teach Us About Marketing?" Australian and New Zealand Marketing Educators Conference Proceedings, Wellington NZ, December.

Bloom, J.W. (2001). "Chaotic and Complex Systems in Children's Thinking and Learning." Paper read at Annual Meeting of the American Educational Research Association, April, at Seattle, Washington.

Boud, D. (1989). "Some Competing Traditions in Experiential Learning." In Making Sense of Experiential Learning, edited by Weil, S. and McGill, I. Buckingham: The Society for Research into Higher Education and Open University Press, 38-49

Brown, J. and Duguid, P. (2000) The Social Life of Information, Harvard Business School Press.

Burbules, N. C. (1993), Dialogue in Teaching: Theory and Practice, Teachers College Press

Carr, W. and Kemmis, S. (1990). Becoming Critical: Education, Knowledge and Action Research . Geelong: Deakin University

Collins, A. (1991). “The Role of Computer Technology in Restructuring Schools.” Phi Delta Kappan, 73,28-36.

Colón, B., Taylor, K. and Willis. J (2000) "Constructivist Instructional Design: Creating a Multimedia Package for Teaching Critical Qualitative Research” The Qualitative Report, 5, 1 \& 2, (http://www.nova.edu/ssss/QR/QR5-1/colon.html) 
Dexter, S., Anderson, R. E., \& Becker, H. J. (1999). “Teachers' Views of Computers as Catalysts for Changes in their Teaching Practice." Journal of Research on Computing in Education, 31 (3), 221-239.

Eakin, J. and Mykhalovskiy, E. (2004) "Teaching Against the Grain: the Challenge of teaching Qualitative Research in the Health Sciences" Conference Report: A national Workshop on teaching Qualitative research in the Health Sciences" Toronto [43 paragraphs]. Forum Qualitative Sozialforschung / Forum: Qualitative Social Research [On-line Journal], 6(2), Art. 42. Available at: http://www.qualitative-research.net/fqs-texte/2-05/05-2-42-e.htm

Ereaut, G. and Imms, M. (2002) "Bricoloage: Qualitative Market Research Redefined," Admap, 434, 46.

Flick, U. (2006) An Introduction to Qualitative Research Methods, Sage, Newbury Park.

Fosnot, C. T. (1996). Constructivism, Theory, Perspectives, and Practice. New York: Teachers College Press.

Fullan, M.G. (1992). Successful School Improvement. Bristol, PA: Open University Press.

Gough, N (1999) “Understanding Curriculum Systems", in Henderson, J. and Kesson, K. (eds), Understanding Democratic Curriculum Leadership, 47-69, Teachers College Press, New York

Hase, S. 2005 “Action Research and Action Learning: A Post Post-Modernist Opportunity Paper" Presented at the ITP New Zealand Conference, Wellington

Heise, D. and Lewis, E (1988) Ethno Documentation Dubuque, Iowa: Wm. C. Brown Publishers

Hunt, S. (1984) "Should Marketing Adopt Relativism? AMA Winter Educators Conference.

Hunt, S. (1990) "Truth in Marketing Theory and Research", Journal of Marketing 54 (3) 1-15

Hunt, S. (1992) "For Reason and Realism in Marketing" Journal of Marketing 56 (2) 89-102

Kemmis, S. 1985. “Action Research and the Politics of Reflection.” In Reflection: Turning Experience into Learning, edited by Boud, D., Keogh, R. and Walker. D. London: Kogan Page.

Kemmis, S., and McTaggart, R. (1988). The Action Research Planner. Geelong: Deakin University Press.

Kolb, D. (1984). Experiential Learning: Experience as the Source of Learning and Development . Englewood Cliffs: Prentice Hall.

Lissack, M. (1999) “Complexity: The Science, its Vocabulary and its Relation to Organizations." Available: http://emergence.org/Complexity1.htm [2000, 2nd December].

Means, B., Olson, K., \& Singh, R. (1995). "Beyond the Classroom: Restructuring Schools with Technology". Phi Delta Kappan, 77, 69-72.

Mehlinger, H. (1996). "School Reform in the Information Age". Phi Delta Kappan, 77, 400-407.

Miles, M. and Huberman A. (1993) Qualitative Data Analysis: A Source Book of New Methods $2^{\text {nd }}$ ed. Sage

Newman, D. (1992). "Technology as Support for School Structure and School Restructuring”. Phi Delta Kappan, 74, 308315.

Peter, J (1992) "Realism or Relativism for Marketing Theory and Research: A comment on Hunt's Scientific Realism” Journal of Marketing 56 (2) 72-79

Phelps, R. (2004) “The Potential of Reflection in Studying Complexity 'In Action'” Proceedings of the 2004 Complexity Science and Educational Research Conference Sep 30-Oct 3 • Chaffey's Locks, Canada • 253-266• www.complexityandeducation.ca

Phelps, R. (2005), “The Potential of Reflective Journals in Studying Complexity 'In Action' Complicity: An International Journal of Complexity and Education 2 (1) 37-54 • www.complexityandeducation.ca

Phelps, R., and Hase, S. (2002). "Complexity and Action research: Exploring the Theoretical and Methodological Connections". Educational Action Research 10 (3) 503-519.

Richards, J., Platt, J. and Platt, H. (1992). Longman Dictionary of Language and Applied Linguistics, Harlow, Longman

Rist, R. (1983) "Transmitting the Craft of Qualitative Research" Anthropology and Education Quarterly. 14, 3, Teaching Fieldwork to Educational Researchers: A Symposium 202-205

Rosenhead, J. (1998) “Complexity Theory and Management Practice”. Available: http://www.human-nature.com/scienceas-culture/rosenhead.html [2000, 2nd December].

Schön, D. (1983). The Reflective Practitioner. New York: Basic Books.

Schön, D. (1985) - The Design Studio: An Exploration of Its Traditions and Potentials International Specialized Book Service Inc

Sheingold, K. (1991). "Restructuring for Learning with Technology: The Potential for Synergy.” Phi Delta Kappan, 73, 17 $-27$.

Siegel, H. (1988) "Relativism for Consumer Research? (Comments on Anderson)" Journal of Consumer Research June 129-32.

Stacey, R., Griffin, D. and Shaw, P. (2000). Complexity and Management: Fad or Radical Challenge to Systems Thinking? London: Routledge.

Tinson, J. (2005) “Looking for Honey Bees," Association for Qualitative Research Journal, March. (www.arq.org.uk/inbrief/document.shtml?doc=julie.tinson.14-01-2005.honeybees)

Webb, R., \& Glesne, C. (1992). “Teaching Qualitative Research”. In LeCompte, M., Millroy, W. \& Preissle, J. (Eds.). The Handbook of Qualitative Research in Education (pp. 771-814). San Diego, CA: Academic Press.

Whiting, M. (2005) "From Insight to Instinct," Research World, June.

Wilkinson, I. and Young, L. (2002) "On Cooperating”, Journal of Business Research 55, 123-133

Wilkinson, I. and Young, L. (2004) "Improvisation and Adaptation in International Business Research Interviews" Chapter 4 in Marschan-Piekkari, R. and Welch, C. (eds) Handbook of Qualitative Research Methods for International Business, Cheltenham, UK and Northampton, MA: Edward Elgar. ISBN 1843760835. 
Zinkham, G. and Hirscheim, R. (1992) "Truth in Marketing Theory and Research: An Alternative Perspective” Journal of Marketing 56 (2) 80-88

\section{About the Authors}

Dr. Louise Young

Louise has had a very successful career both as a teacher, and as a researcher, as is reflected in the awards she has received, most recently as a co- recipient of a Carrick Citation for "for sustained development of student inspiration, achievement and curiosity through their engagement in a practice-based, research-led group project" and her position as Professor in the School of Marketing at the University of Technology, Sydney. She regularly runs workshops, both in Australia and overseas, on a variety of topics including qualitative research methods Louise's many publications reflect the breadth of her research interests; from the nature of teaching to the nature of complex systems. She is widely recognized as an expert on the nature and role of trust in relationships and is involved in a number of international projects in this area Current research focuses on the evolution and management of relationships and networks in a range of contexts including business to business, tourism and CSR.. Research methods used include deep qualitative interview and lexicographic analysis and agent-based modeling.

\section{Lynne Freeman}

After completing a master's degree in Marketing Education, from the University of Lancaster, Lynne gained several years experience in the market research industry in the UK, where she specialised in retail and panel research. Lynne moved to Australia in the mid 1980's and since her arrival has taught at both the graduate and undergraduate level, run workshops and training courses on amongst other topics qualitative research techniques, small business governance and market research skills, given seminars both here and overseas on communication and Government policy. She has received awards for her teaching, most recently being co-awarded a Carrick Citation for "outstanding commitment to student learning" She also runs a consultancy specialising in qualitative market research. Research interests include qualitative research, education, compliance, marketing communications, small business management and taxation. 
Copyright of International Journal of Learning is the property of Common Ground Publishing and its content may not be copied or emailed to multiple sites or posted to a listserv without the copyright holder's express written permission. However, users may print, download, or email articles for individual use. 
Copyright of International Journal of Learning is the property of Common Ground Publishing and its content may not be copied or emailed to multiple sites or posted to a listserv without the copyright holder's express written permission. However, users may print, download, or email articles for individual use. 